\title{
An Investigation Study of Hospital Management Information System
}

\author{
Dr. Mohammed Najm Abdulla ${ }^{1}$, Dr. Intisar Al-Mejibli ${ }^{2}$, Shaimaa Khamees Ahmed ${ }^{3}$ \\ Computer Engineering Dept., University of Technology, $\operatorname{Iraq}^{1}$ \\ Informatics System Management Dept., UOITC, Iraq ${ }^{2}$ \\ Institute for Postgraduate Studies, UOITC, $\mathrm{Iraq}^{3}$
}

\begin{abstract}
Healthcare is so interesting for our society. Generally Hospital Management Information System(HMIS) is a computer-based system that has the ability to coordinate all information for enable healthcare providers to do their works effectively and efficiently. According to using these systems across the globe, this requires a strong need to understand such systems and its capabilities. This work conducts investigation study about hospital management information system encompasses historic view of the system and its evolution stage, the most important functionalities services, stakeholder of such systems, components of HIS, three layer graphic based model(3LGM), architecture design style of HIS and standard communication of HIS. This work will give a comprehensive picture to the reader about available HMIS.
\end{abstract}

Keywords: Hospital Information System (HIS), Health Management, Heath level 7(HL7), 3LGM.

\section{INTRODUCTION}

Generally Hospital management information systems have retrieving information encountered by the traditional the function of patient are and hospital management [1]. hospital system in order to improve the overall efficiency These functions include: keeping information about the of the organization[12][3][13].In spite of these benefits, patients, generating bill, maintenance schedule of the trip of transforming to this perfect system is mixed equipments in the hospital, recording information related with challenges. These challenges start from problems to diagnosis given to patients, keeping record of the appearfrom the very nature of healthcare information, immunization provided to patient, keeping information ending with the problems related to complexity healthcare about various diseases and drugs available to treat them information technology, and its user [13].Many etc.[2][3][4]. Previously, all these different functions are researchers' studies have been done on HMIS in different done by operational cadre and doctors manually on paper directions and various attentions.[2]Proposed HMIS [4]. With the increase of demands on health care services development by using Structure Query Language (SQL) because of increasing in population paired with increasing forkeeping the records in the database and uses JAVA as attention over patients' safety and the way to treat them, it the front-end software which has connectivity with My became so hard to do all these works manually[5][6]. SQL, the back-end software. Whilein [14] service oriented Beside of these factors the rapid and various advances in architecture(SOA) was employed to design an integration Information and Communication Technology (ICT) which HIS.The authors in [15] and [16] have used intelligent occupying the leading position and represent the main agent technology. These agents used to provide correct factor for shift from manual to electronic system, the information that help in diagnostic and treatment.This existence of electronic HMIS became essential to research was proposedto give a comprehensive picture for automate all these operations [7][8][9]. According to [10] HMIS. The research aims to:

[11] HIS was defined as an integrated computer system to 1-explain the main component of HIS and its functions. store, manipulate, manage and retrieve clinical, and 2-describe the architecture design style of HMIS.

administrative information in healthcare organization.[8] 3-identify the criteria quality of structures for HMIS, and View the hospital information system as the entire 4-list the main factors that contribute in successful HMIS. information processing and information storage subsystem of a hospital, whereby it is not just about computer systems and networks and the computer-based application systems that are installed on them, but it is about the information in a hospital as a whole. It have the advantages of increase legibility, reduce medical errors, shrink costs and boost the quality of healthcare and eliminate the problem of inappropriate data keeping, inaccurate reports, time wastage in storing, processing and

\section{HOSPITAL MANAGEMENT INFORMATION SYSTEM (HMIS)}

\section{A-Background}

Healthcare management points to a procedure wherein the health risk elements threatening individuals and groups aremanaged in a complete and integrated method. It targets to get people and groups extra energetic to take 
Vol. 6, Issue 1, January 2017

advantages of restrained assets to cause them to more healthy [17]. Since healthcare information systems and health information systems are similar concepts, a lot of acronyms have been used through the development of such system. Although there is no obvious agreement by all in literature till lately, the term health information systemsis similar to multiple previous form of this concepts like hospital information systems. At the same way ,terms like Computerized patient records, electronic medical records, in addition to the currently electronic health records that have been come to be popularly used almost interchangeably [13].The main evolutionary developments of hospital informationsystems from the early stagesto the health information systems as known currently have been discussed by[18][13]. The following paragraphs addressed the important evolution directions of health information system:-

- Direction 1: From Paper-Based Systems to Computer-Based Systems: through the past decades health data and information have been created and stored primarily on paper, there has beenanobvious shifting from paper to computer-basedsystems .This capability refers to that much data could be processed and stored by the use of modern information technologies to produce better knowledge. The future of healthcare information systems aims to benearly“"paperless" era[18][13].

- Direction 2: From Local to Global Information Systems: however the early healthcare informationsystemwasspecific to departments unit(e.g. radiology, or laboratory) or just througha healthcare practice system (e.g. hospital orclinic) contemporary healthcare systems aims to be regional, national and also a across globe[13][9].

- Direction 3: From Healthcare Professionals to Patients and Consumers: in the original, healthcareinformation systems were developed to beused by mainly physicians in addition to administrativestaff but after that it waspassed on to be used by nurses. Sincethen, the direction has shifted to encompasses more patientinput.[18]

- Direction 4: From Using Data of Patient Care to Research: additional change has been done in using data. Through the last years, patient data hasbeen used specially for patient care management. Currently extend the possibility of using data, firstly used for patient care, as well as for healthcare planning and above all these things for research and education [13]

- Direction 5: From Technical to Strategic Information Management Orientation: according to[13][18][9] it has been noted that while computersupportedinformation systems from the 1960sto the 1990s focused on troubles resultingfrom the technical issues of the systems, concernsabout the organizational problems, socialissues and change management issues becamemore relevant at the turn of the millennium.
- Direction 6: From Numeric(simple) Data to complicatedtype of Data: this is not limited ontechnology that support health informationsystems advanced in technological complexity, it also implies the data that has been received and processedhas become complex too. Changing from numeric data through alphanumeric data to imaging and even molecular data[13].

\section{B-Definition of HMIS}

HMISis a system for patient care and hospital management. Most hospital information systems (HIS) in advanced countries are comprehensive, integrated and specialized information systems has been developed to help in achieving best clinical outcomes, perfect financial performance and most importantly patient and employee satisfaction. They are regarded one of the most important focal points on which the delivery of healthcare within hospitals and different types of medical institutions depends[19, 20].The hospital management system (HMS) consists of a computerized web based application in order to record storing, tracking and prescriptions with monitoring[3]. Broadly classification of HMIS can be categories according to type of functions that could be offered into four categories namely patient care services, clinical services, hospital Admin and Ancillary services as illustrated in Fig.1[20].

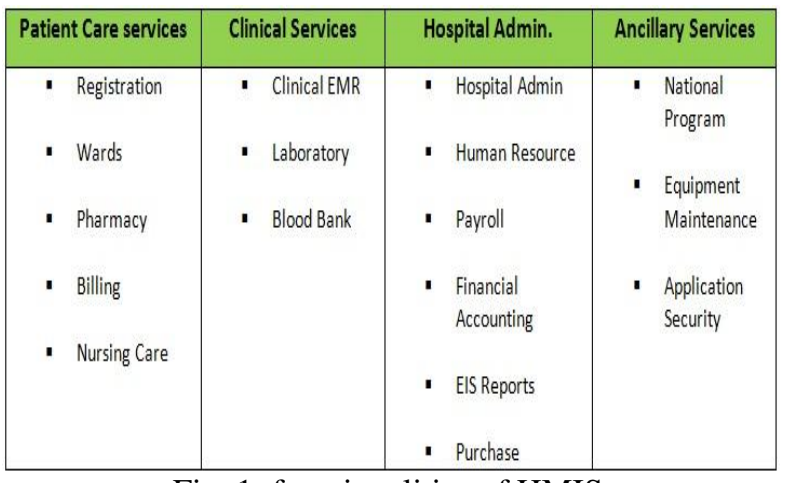

Fig. 1: functionalities of HMIS

Form a services or the functions view point, the major areas that constitute HIS according to[21]are:-

The administration and management area, which provides strategic and administrative functions; the front-office area, which provides the admission of inpatients, outpatients, or emergency/first aid patients; the clinical area, which provides the core healthcare, services (the processes by which patients can get treatment from health care organizations).

Fig 2 illustrate the complete picture of the different area and how they are interconnected and integrated with each other by the with so called middleware layer.

\section{C- HMIS Stakeholders}

It is very important to determine the IS users. All users of an HIS are stakeholders who are involved in its operation 
and functionality. According to [10] HIS users category include:

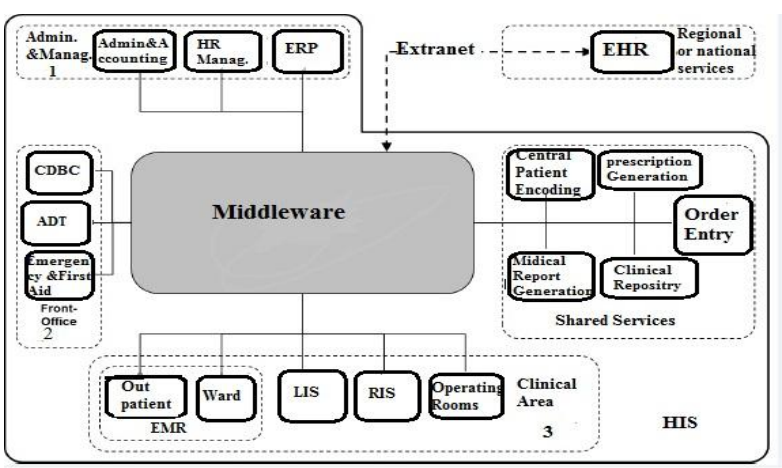

Fig. 2 .Conceptual Architecture of a HIS

1- Internaluser: the nursing staff, doctors, the administrative staff, and generally all those directly related to HIS use are grouped under internal users.

2- $\quad$ Externalusers: the patients, suppliers, insurance providers, and everyone that is indirectly related to an HIS belong to external user group.

\section{D-Components of Hospital Information Systems}

Asystem can be defined as collection of elements or components that are organized for a common purpose. Typical components of hospital information systems are:

1. Information processingcomponents that imply:

a. enterprise functions: describes the role of human or machines that should be played in a particular enterprise which assist in achieving its mission and aimseg.(patient admission)

b. business process: to determine theorder and logical sequence of set of activities

2. Information processing tools that imply:

a. application components: support enterprise function and controlled by application program

b. physical data processing components :eg.(servers, terminal)[22]

E-Three layer Graph-based Meta model (3LGM) for 2 Modelling HIS:

As described in[22] this metamodel is called the threelayer graph-based metamodel(3LGM). Its primary goal wassupporting the organized management of HIS in addition to the quality assessment of information processing in hospitals. Unified Modeling Language (UML) notation was used to represent 3LGM.Itlinks a functional metamodel with technical metamodels according to [22].Three layers of information systems can be recognized to 3LGM include: domain layer, logical tool layer, and physical tool layer as stated in [23][22][24]. In keeping with [8]the domain layer describes a hospital independently of its implementation as set of enterprise functions. The logical tool layer describes application components. Application components help enterprise or hospital functions and provide the services oftransformation, storage and communication of data. On the physical tool layer there is a set of physical data processing components that are used to realize the computer-based and the paper-based application components.

\section{ARCHITECTURE DESIGN}

Design architecture style of HMIS can be classified according to the no. of application components (functions) that could be supported by the system to:

1. HMIS Systems with one or little homogeneous application component(software product) suitable for small to medium hospital:

comprises only one database to store all patient-related data.Theused network architecturein these systems is centralize database with client server(two tier) architecture which is include one or more mainframe server connected with multiple terminals/workstations. The accessing process to the application component (Patient Registration, Accounting and Finance, Billing, Laboratory, Radiology, HumanResource Pay Rolls, Stores and Pharmacy) that is installed on the framework can be done by using the terminals. These workstation does not have their own data processing services[22][25].Fig.3 depict this type of architecture

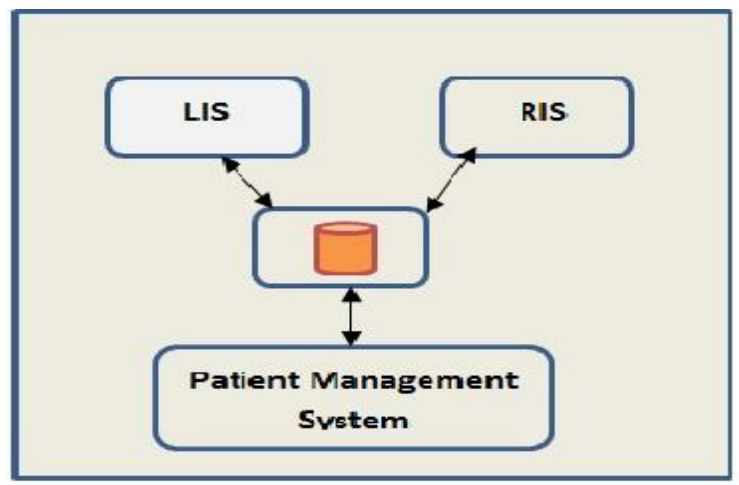

Fig.3. architecture of centralizeddatabase system

2. HMISSystem withmany heterogeneous applicationcomponent(software product)suitable for large hospitals and many hospitalspreading over distributed location:

The network architecture used in this type isthree tierclient-server architecture and distributed database architecture style.Several application components store data about certain entity types persistently and contains their own databases.central servers are interconnected through the network. The servers could be for instance application file servers that keeping various application components or database servers which keeping data of multiple application components. Both server types may be combined in one physical server. Various workstations are connected to this network. The server introducesfunctions that can be accessed by the workstations as clients. The workstations are typical 
Vol. 6, Issue 1, January 2017

personal computer system withits own memory and data processing unit. Theycan offer access to application components installed on the application file server as well as to locally installed application components[22][26].Fig 4 illustrates this type of database architecture style.

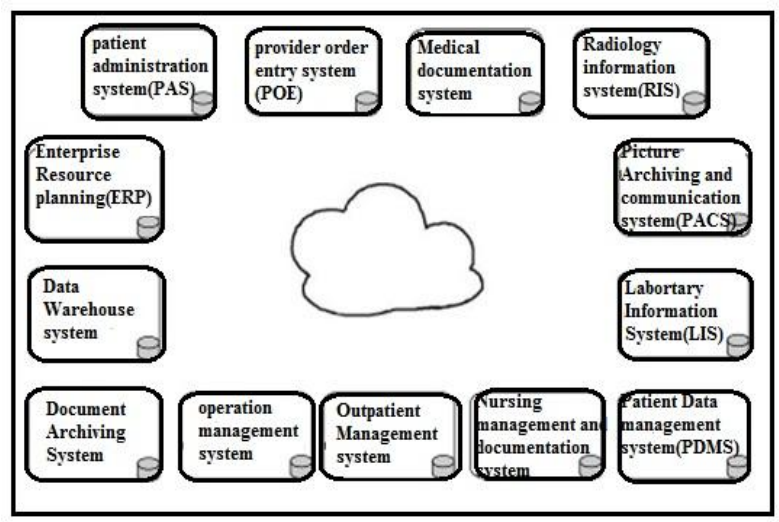

Fig.4. Distributed architecture style

The three tier architecture which has been deployed in this type has the ability to make changing of any tier with no effect the other two tier. Central servers connected to the local server for each hospital. The local server has the ability to work independently. when the day has been ended itwould push in data to the centralized servers[27]. The three tier architecture was depicted in Fig. 5 below.

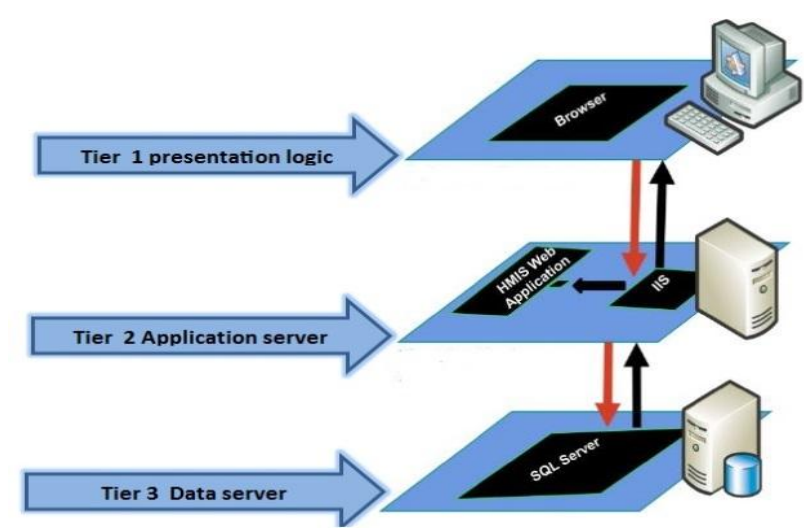

Fig. 5.Three tier architecture of HMIS solution

Furthermore,the layered architecture style which partition the application into stacked groups/layers has been adopted in designing the integrated HMIS according to[14, 28][29]. These layers which constitute the architecture namely: infrastructure layer, datalayer, integrationlayer, application layer, communication layer and user layer as illustrated in Fig.6. Belowis brief explanation for each layer.

1- Infrastructure/resourcelayer: theInfrastructure Layer include the computer hardware (desktop, Server, peripheral devices, UPS, etc.); civil infrastructure designed for (control center,server room, etc.) and network infrastructure (switcher,cable, router, fiber optic channel, etc.).[14]
2- The Data Layer is composed by required databases like a GIS database (references map, roads map); A database to store logs and records of past and ongoing records; Other related databases and a system database to manage records etc.[14]

3- integration layer/middleware: Middleware is an approach to distinguished problems which include heterogeneity, dependability, interoperability, decision support, and security [30]located between application layer and infrastructure layer/resource layer(extended to operation system)[14].It consist of a set of standard andassociated object classes that provide component communication, data staging and information exchange[22][28, 31] .

4- Application layer: support the interaction with the user. Itincludes the application that provides the user with functions. It integrate functions into modules that would be introduced to communications carriers[28][14].

5- Communication layer: define communications carriers. 6- User layer: represents the user of the systems[14].

System development process has been done by using different technologies and deployment over large distributed distances.SOA approach was adopted to integrate such different systems [31][28].SOA in addition to web services coordinates all the issues of creating and using software services during the software system development [14]

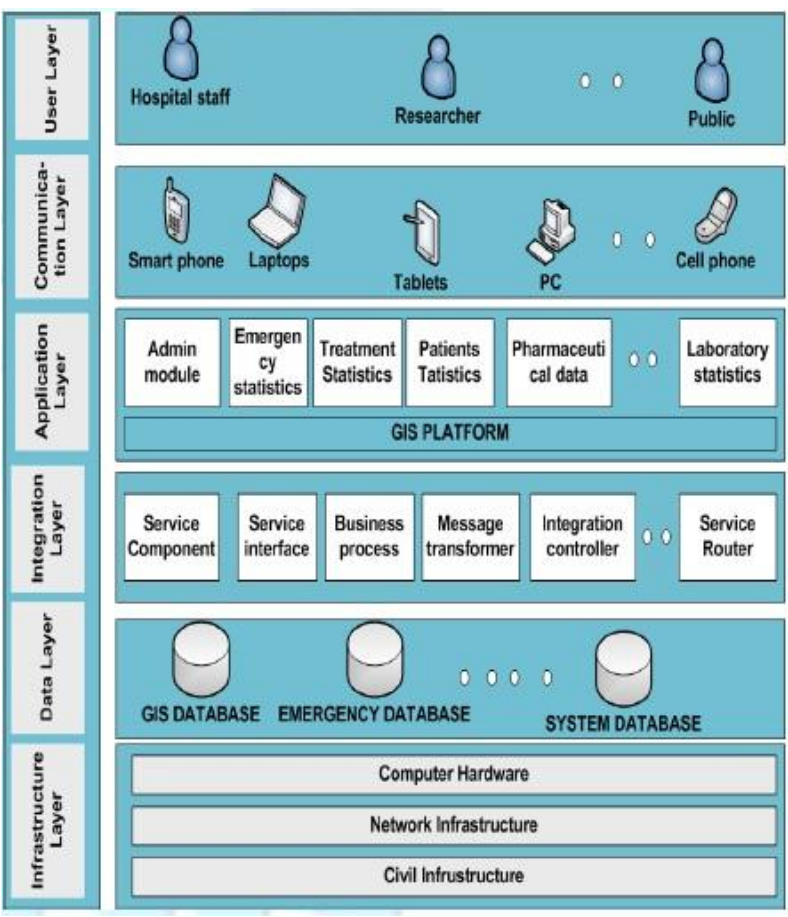

Fig.6. the layer architecture for hospitals

\section{HMIS COMMUNICATION STANDARD}

Regardless the technology for integration used application components have to communicate if they shall be 
Vol. 6, Issue 1, January 2017

integrated. A consensus must exist about the syntax and semantics of the data and messages that are to be exchanged. The most important standards for communication inside hospital information systems are HL7, DICOM.

\section{1- Heath level 7(HL7)}

Standard HL7 is one of various American National Standards Institute (ANSI) authorized Standard Developing Organization, operating in the healthcare sector worldwide. ("Level Seven" point to the highest level of the International Standards Organization's (ISO) communications model for Open Systems Interconnection (OSI) the application level.)[8].It has the ability to providethe common language for information exchange and electronic patient records in both internally and externally[32].The vision of HL7 is to build an infrastructure for interoperability in the healthcare domain. HL7 employ the reference information model (RIM) to derive domain specific information models and process them into HL7 message specifications [8, 22].

HL7 aims to use of such standards within and between health care organizations to growth performance of health care functions such a way that is in desire of all. This meansthat HL7 aims to facilitate communication in configuration Health Care. HL7 Standardshavemuch flexibility information exchange in both of the hardware and software infrastructure[33].

\section{2- Digital Imaging and Communications in Medicine (DICOM)}

According to [22]Digital Imaging and Communications in Medicine (DICOM)50 is a standard maintained by the International DICOM Committee that identify the integration requirements of the medical imaging sector.The standard encompass file and message formats for:

- kinds of medical imaging modalities (e. g., computed tomography, digital $\mathrm{x}$-ray, magnetic resonance imaging, ultrasound, nuclear medicine imaging etc.),

- a network protocol and

- a variety of well-described services

These services, for example, permit:

- an imaging format to restore a "worklist" depicting the patients to be checked from the Radiological information system (RIS),

- to transfer the images and x-ray dose information maded through an inspection to the PACS,

- to emphasize that the images have been archived correctly (and can thus be removed locally) and

- to inform the RIS that the imaging procedure has been finished.

Key Aspects Contributing to Successful Hospital FM

Diverse research have proposed key elements that could make a contribution to the success of hospital FM. In general those factors include eight elements as listed in [34].

\begin{tabular}{|c|c|}
\hline $\begin{array}{l}\text { (1) Management } \\
\text { of information and } \\
\text { knowledge }\end{array}$ & $\begin{array}{l}\text { (2) Fitting } \\
\text { function and role to the } \\
\text { environment of practice }\end{array}$ \\
\hline $\begin{array}{l}\text { (3) Sufficient } \\
\text { budget and cost } \\
\text { effectiveness }\end{array}$ & $\begin{array}{l}\text { (4) Selecting and } \\
\text { dealing with the outsourcer }\end{array}$ \\
\hline $\begin{array}{l}\text { (5) Leadership } \\
\text { and experience of } \\
\text { facilities manager }\end{array}$ & $\begin{array}{l}\text { (6) Facilities } \\
\text { managers' involvement in } \\
\text { hospital level decision- } \\
\text { making }\end{array}$ \\
\hline $\begin{array}{l}\text { (7) Staff } \\
\text { development } \\
\text { training }\end{array}$ & $\begin{array}{l}\text { Service } \\
\text { standardization } \\
\text { benchmarking }\end{array}$ \\
\hline
\end{tabular}

\section{CONCLUSION}

This research presented a complete view to the HMIS as it has been specified the definition of HMIS withits main functions.Stakeholders of the system have been determined. Metamodel for modeling HMIS which is 3LGM and architecture was explained with design styles which could be adopted according to the requirement specification for each system. Lastly, the key factors that contribute in designing and implementingefficient HMIS are stated.

\section{REFERENCES}

[1] Sunil_R._Avashia “www.cips.org.in/documents/2014/SPIPA/ hospitalmanagement system," 2014.

[2] O. Olamide.O, E. A. W, and O. A. A, "Design and Implementation of Hospital Management System Using Java," Figshare, 2015.

[3] A. O.A, O. D.A, B. O. A. and, and O. Y.V, "Design and Implementation of Hospital Management System," International Journal of Engineering and Innovative Technology (IJEIT), vol. Volume 5, no. Issue 1, 2015.

[4] M. Chitkara, N. Khandelwal, and A. Chaporkar, " https://www.scri bd.com/doc/13569522/09-Project-Hospital-Management-System."

[5] O. N. AGNES, "AUTOMATED HOSPITAL MANAGEMENT SYSTEM," 2011.

[6] N. S. Lucas, and D. Rojas, "A systematic review of proactive health management and empowerment for senior citizens." pp. 1-8.

[7] D. Shah, and A. Bakshi, "REVIEW ON HOSPITAL MANAGEMENT SYSTEM.”

[8] P. Balaraman, and K. Kosalram, "E-Hospital Management \& Hospital Information Systems-Changing Trends," International Journal of Information Engineering and Electronic Business, vol. 5, no. 1 , pp. 50, 2013.

[9] M. N. Almunawar, and M. Anshari, "Health Information Systems (HIS): Concept and Technology," arXiv preprint arXiv:1203.3923, 2012.

[10] M. Mahdavian, H. Nazarian, M. Mahdavian, and N. Wattanapongsakorn, "An investigation of the success of hospital information systems implementation: A case study." pp. 329-333.

[11] note, "availabe on http://medicaldictionary.thefreedictionary.com/hospital+information+system."

[12] E. Mehraeen, M. Ahmadi, Y. Mehdipour, and T. Noori, "EVALUATION OF HOSPITAL INFORMATION SYSTEMS IN SELECTED HOSPITALS OF IRAN," International Journal of Advanced Information Technology, vol. 4, no. 5, pp. 1, 2014.

[13] M. Khosrow-Pour, Encyclopedia of Information Science and Technology, Third Edition: IGI Global, 2014.

[14] Q.-A. Kester, "Using SOA with Web Services for effective Integration of Hospital Information Systems via an Enterprise Service Bus," arXiv preprint arXiv:1307.7790, 2013. 
[15] V. G. Koutkias, I. Chouvarda, and N. Maglaveras, "A multiagent system enhancing home-care health services for chronic disease management," IEEE Transactions on Information Technology in Biomedicine, vol. 9, no. 4, pp. 528-537, 2005.

[16] H. O. Al-Sakran, "FRAMEWORK ARCHITECTURE FOR IMPROVING HEALTHCARE INFORMATION SYSTEMS USING AGENT TECHNOLOGY," International Journal of Managing Information Technology, vol. 7, no. 1, pp. 17, 2015.

[17] C. Pei-you, and Z. Wang, "The Design and Analysis about Personalized Health Management Service System." pp. 1-6.

[18] R. Haux, "Health information systems_ past, present, future," International Journal of Medical Informatics, pp. 268-281 2006.

[19] M. Khalifa, and O. Alswailem, "Hospital Information Systems (HIS) Acceptance and Satisfaction: A Case Study of a Tertiary Care Hospital," Procedia Computer Science, vol. 63, pp. 198-204, 2015.

[20] B. Murthy, P. Srivastava, and A. Cheema, "Implementation challenges of hospital information system in super specialty hospital "A case study of PGIMER, Chandigarh"." pp. 77-82.

[21] P. Locatelli, N. Restifo, L. Gastaldi, and M. Corso, "Health care information systems: architectural models and governance," Innovative information systems modelling techniques, pp. 73-98, 2012.

[22] R. H. A. Winter, and E. A. B. Brigl, Strategic InformationManagement in HospitalsAn Introduction to HospitalInformation Systems, Verlag New York: Springer, 2004.

[23] G. Hubner-Bloder, E. Ammenwerth, B. Brigl, and A. Winter, "Specification of a reference model for the domain layer of a hospital information system," Studies in health technology and informatics, vol. 116, pp. 497-502, 2005.

[24] B. B. A.Winter, T.Wendt, "modeling hospital information system the revised Three -layer Graphic-Based metamodel 3LGM," 2003.

[25] S. M. H. B. Shakeel.M, "A Study on Hospital Information System at a Tertiary TeachingHospital," Global Journal of Computer Science and TechnologyInterdisciplinary, vol. 12 no. 10, 2012.

[26] M. T. Ö. P. Valduriez, Principles of Distributed Database Systems, Third Edition ed., 233 Spring Street, New York,

NY 10013, USASpringer Science+Business Media, LLC, 233 Spring Street, New York,NY 10013, USA, 2011.

[27] O. F. India, "Hospital Management Information System, Gujarat

Documentation of Best Practice," OneWorld Foundation India, September, 2012.

[28] H. Rajasekaran, L. L. Iacono, P. Hasselmeyer, J. Fingberg, P. Summers, S. Benkner, G. Engelbrecht, A. Arbona, A. Chiarini, and C. M. Friedrich, "@ neurIST-Towards a System Architecture for Advanced Disease Management through Integration of Heterogeneous Data, Computing, and Complex Processing Services." pp. 361-366.

[29] B. Chowdhury, and R. Khosla, "RFID-based hospital real-time patient management system." pp. 363-368.

[30] A. Pir, M. U. Akram, and M. A. Khan, "Internet of things based context awareness architectural framework for HMIS." pp. 55-60.

[31] I. Sommerville, SOFTWARE ENGINEERING, Ninth Edition ed.: Pearson Education, Inc., publishing as Addison-Wesley.

[32] S. Aghazadeh, A. Aliyev, and M. Ebrahimnezhad, "Review the Role of Hospital Information Systems in Medical Services Development," International Journal of Computer Theory and Engineering, vol. 4, no. 6, pp. 866, 2012.

[33] A. A. S. Aghazadeh, and M. Ebrahimnezhad, "Review the Role of Hospital Information Systems in Medical Services Development," International Journal of Computer Theory and Engineering, vol. 4, December 2012.

[34] L. S. Pheng, and Z. Rui, Service Quality for Facilities Management in Hospitals: Springer Singapore, 2016. 